THE OLIVIERI SYMPOSIUM

\title{
Better governance in academic health sciences centres: moving beyond the Olivieri/Apotex Affair in Toronto
}

\author{
L E Ferris, P A Singer, C D Naylor
}

See end of article for authors' affiliations

J Med Ethics 2004;30:25-29. doi: 10.1136/jme.2003.005181

Correspondence to:

Dr L E Ferris, Department

of Public Health Sciences,

University of Tornoto, 12

Queen's Park Cres. West,

McMurrich Building,

Fourth Floor, Toronto,

Ontario, Canada,

M5S 1A8.

lorraine.ferris@utoronto.ca

Revised version received 9 June 2003

Accepted for publication

17 June 2003
The Toronto experience suggests that there may be several general lessons for academic health sciences complexes to learn from the Olivieri/Apotex affair (OAA) regarding the ethics, independence, and integrity of clinical research sponsored by for profit enterprises. From a local perspective, the OAA occurred when there already was a focus on the complex and changing relationships among the University of Toronto, its medical school, the fully affiliated teaching hospitals, and off campus faculty because of intertwined interests and responsibilities. The OAA became a catalyst that accelerated various systemic reforms, particularly concerning academic/industry relations. In this article, the evolving governance framework for the Toronto academic health sciences complex is reviewed and these policy and process reforms discussed. These reforms have created collaborative activity among research ethics boards and contract research offices of the partner institutions, and allowed the joint university/hospital ethics centre to play a role in governance and policy, while respecting the missions and mandates of the involved institutions. Although few of the policies are dramatically innovative, what is arguably novel is the elaboration of an overarching governance framework that aims to move ethics to a central focus in the academic complex. Time alone will tell how sustainable and effective these changes are.
A $s$ this symposium illustrates, the Olivieri/Apotex affair (OAA) has afforded continuing opportunities for commentary. Reportage and analysis to date have been interspersed with fingerpointing to "name, blame, and shame" individuals. By analogy with the patient safety and medical quality movements, however, a sustained impact can only be achieved by moving beyond a post hoc paradigm with the bioethicist as would be watchdog, and implementing better systems based on good governance, preventive ethics, institutional learning, and continuous policy improvement.

The University of Toronto ("the university"), its medical school, and the fully affiliated teaching hospitals ("the hospitals")—working together through the Toronto Academic Health Sciences Council (TAHSC)—have accordingly implemented systemic policy reforms built in part on the OAA experience with respect to the academic/industry interface. ${ }^{12}$ The OAA has been a high profile catalyst for some of these reforms. Also, however, this dispute occurred at a time when the landscape of the academic health sciences complex in Toronto had shifted, owing to two decades of underfunding of provincial postsecondary education, coupled with a major increase in hospital based research activities and a shifting of undergraduate medical education, graduate students, and postdoctoral fellows to the hospitals. Recent university/hospital policy reforms accordingly reflect ongoing dialogue about roles and responsibilities in the academic health science partnership.

These systemic reforms aim at establishing "good governance" in the health science complex-that is, effective and accountable institutional actions based on appropriate shared ethical intentions. ${ }^{3}$ Integral to this framework is the recognition that while the ethical tenets governing the institutions are shared, the university and the hospitals each have somewhat distinct missions and mandates requiring policy reforms to balance the autonomy and responsibilities of these partners.

We begin with a review of the governance framework for the Toronto system, and then turn to policy and process reforms in the Toronto academic health sciences centre, grouped under research, education, and clinical/organisational affairs. ${ }^{4}$

\section{The governance framework}

Organisational relationships among universities, medical schools, and teaching hospitals in North America are varied. At the core of these relationships is a social contractmedical schools need access to hospital facilities to offer clinical and practical experience to medical students and residents, and teaching hospitals need access to university services, resources, and academic appointments for their research and teaching. Across North America, the organisational relationship is further complicated because clinical faculty seldom receive more than a fraction of their compensation from their host university. Instead, these clinical faculty are typically paid a salary for clinical work by their base hospital and/or receive compensation for clinical services through practice plans that manage revenue flows from public and/or private prepayment schemes. In many centres, the majority of clinical faculty are effectively self employed and their practice plans constitute a "third force" along with the university and the hospitals in governance and economic arrangements.

The organisational structures of academic health sciences complexes vary with local history, politics, and economics. ${ }^{56}$ Organisational structures range from operational aggregation-for example, a university, its medical school, and the teaching hospitals operate under one identity, to operational disaggregation-for example, a university, its medical school, and the teaching hospitals are governed more or less separately from each other, with varying models characterised by more or less university involvement in the inner workings of an academic medical complex. ${ }^{5}$ Where the hospitals are autonomously governed, the collaboration with a university and/or medical school is typically codified in an affiliation or a partner agreement. Furthermore, practice plans may be autonomous from, or controlled all or in part by, either the university or the hospital. Both Toronto and Harvard-for example, are characterised by medical schools 
embedded in the host university administratively, independently governed hospitals party to a university/hospital affiliation agreement, and highly autonomous practice plans involving groups of clinical faculty who are more dependent on the clinical resources of their base hospital than on any salary support from the medical school or university.

In Toronto, only $7 \%$ of the average earnings of full time clinical faculty come directly from the university. While hospitals contribute salary support for clinical and academic activities, practice plans are highly autonomous since most of their revenue is derived independently from professional billings to the universal health insurance plan. Practice plans are influenced to some degree by the host hospital because of the salary contributions and the institution's control of clinical resources (beds, operating rooms, etc). The university's influence is achieved through modest salary contributions and, more importantly, by control of university appointments which, in Toronto, are recognised in the affiliation agreement as required for all full time medical staff in major teaching hospitals. Further, practice plans and hospital chiefs desire interinstitutional stability and consistency, and the university facilitates these goals as a multihospital broker.

In recent years steps have been taken to strengthen and clarify the governance and administrative framework among the hospitals and university in Toronto. In education, several hospitals manage three distinct clinical academies for undergraduate medical education, with directors reporting jointly to the hospital vice president for education and the associate dean of undergraduate medical education. A Hospital University Education Coordinating Committee (HUECC) oversees educational matters at the clinical interface. Since the university has primary jurisdiction in education, HUECC reports to the dean of medicine.

In contrast, the Toronto Academic Health Sciences Council (TAHSC) is a vehicle that draws together the hospitals and university for consensus building without direct authority. The council includes the university president, the dean of medicine in his role as vice provost for relations with health care institutions, a representative of other health science deans, and each hospital's CEO. It oversees the partnership arrangement in an effort to clarify shared values, upgrade policies, and achieve policy consistency among institutional partners.

A focus on research related ethics and policies has been driven first by the above noted increase in human subjects research by the hospitals. Second, the university established a Joint Centre for Bioethics (JCB) as a partnership involving all the hospitals. The JCB has avoided a "policing" function and instead aims to shift the local culture concerning the ethics of education, research, and clinical resource allocation. Third, with the growing prominence of industry as a research sponsor and tensions at the academic/industry interface (including the OAA), common policies prevent industrial sponsors from shopping around for the environment most conducive to their particular interests. Fourth, and critically, the Canadian granting agencies joined forces in the 1990s to harmonise their own ethical guidelines for research, leading to the Tri-Council Policy Statement (TCPS) in 1998. The TCPS catalysed improvements and consistency in ethical reviews of research by all the partner institutions.

Starting in 2000, the hospitals and university established several TAHSC working groups that would, on an ongoing basis, address diverse issues in research-for example, ethical conduct of research involving animals; enhanced processes for review of research involving human subjects; elaboration of guidelines for the ethical conduct of research and the management of allegations of research misconduct, and development of consistent policies for contract research that would respect academic values. The TAHSC working groups play a key role in implementation and identification of barriers and as necessary, bring issues forward to the partner organisations for resolution.

In sum, the medical faculty has taken the lead, fully supported by the university central administration and all the hospitals, in developing an enhanced framework for interinstitutional partnership. The partnership respects the lead roles of the university in education, the hospitals in clinical care, and the overlapping nature of responsibility for research. An omnibus agreement between the university and the hospitals commits the parties to harmonisation of research ethics, creating a consistent policy environment, and planning conjointly on all major infrastructure projects. Also included in the agreement are provisions for sharing research overhead funds from the federal government, and division of research monies on a transparent basis according to work done and costs incurred. A codicil to each affiliation agreement embraces harmonisation and continuous upgrading of research policies, while affirming the university's role in graduate education. All TAHSC supported policies are brought forward by each of the partners to their respective administrative and governing bodies for final endorsement. The partners recognise that while the individual institutions are ultimately autonomous and have slightly different missions, they are interdependent and their core values must be aligned and ethically defensible in so far as their missions overlap.

\section{Progress in research ethics}

To achieve policy consistency, the partners have approved a number of revised research policies. The revisions reflect the reality that more research will be conducted by teams and on a multisite basis, that issues of authorship and oversight of complex projects are now more pressing, and that contract research will continue alongside traditional peer reviewed research. The revised policy addressing the principles for ethical conduct of research-for example, speaks more directly to community research, the interface between academia/industry, and good ethical practices on research teams. The revised policy dealing with allegations of research misconduct includes an expansion of the definition of research misconduct to address the need to reveal and manage material conflicts of interest. Institutional conflict of interest is also addressed-when there are allegations of research misconduct involving works or inventions for which the university has a financial interest, the matter may be referred externally by the dean for inquiry and investigation. The new policies clarify processes for making allegations of research misconduct, dispute resolution mechanisms, and jurisdiction in conducting individual inquiries and investigations. A previous guideline on finders' fees has been amplified into a policy that more fully addresses the myriad ways in which sponsors and investigators can build inappropriate incentives into clinical studies budgets.

The partners also have new policies for contract research. Three core principles governing clinical study agreements (CSAs) have been implemented that could well have prevented the entire OAA had they been in place and enforced a few years earlier. First, under no circumstances shall CSAs allow research sponsors to suppress or otherwise censor research results. Investigators must retain the right to publish and to disclose immediately any safety concerns that arise during the study to their research ethics board, patients, and regulators. Second, contracts may require submission of research reports to sponsors before publication to allow protection of intellectual property or debate about the interpretation of the study results; but this step is time limited and cannot become a form of suppression. In general, 
the time from submission to sponsor to submission for publication is no more than 90 days for a single site study and 120 days for a multisite study. A multi-institutional self audit of the implementation of this policy ${ }^{2}$ demonstrates that the TAHSC institutions consistently implemented the harmonised standards for managing CSAs and that with few exceptions, industrial sponsors have agreed to the terms and conditions incorporated to protect academic responsibilities and public safety.

There are ongoing policy revisions and upgrades. It was recently agreed, for example, that Research Ethics Boards should have the right to see any CSAs to ensure that the legal/financial provisions do not cause ethical concerns. All multisite clinical studies must have independent steering committees. Currently, a field test is under way requiring sponsors to demonstrate that they are respecting the publication rights of the overall steering committee before a CSA is signed. Furthermore, the university and the hospitals have streamlined processes for ethical review of study protocols to reduce redundancy and share findings, established an appeal mechanism, and are building a hospital/ university online registry of all clinical studies internally approved or undergoing ethics review.

\section{Progress in educational ethics Undergraduate medicine}

In 2001, an article authored by several university of Toronto medical students identified three types of ethical challenges in medical school: conflicts between medical education and patient care; responsibility exceeding students' capabilities, and involvement in care perceived to be substandard. ${ }^{7}$ The study catalogued some unethical practices that are likely at issue in all medical schools. The study was supported and funded by the deans' offices and the Joint Centre for Bioethics.

St Bartholomew's (Bart's) hospital in London had developed pioneering guidelines to address such issues, ${ }^{8}$ emphasising patients' rights in the clinical educational milieu. The university established a task force, overseen by the HUECC, to develop guidelines for clinical teaching. The task force built on the Bart's guidelines in two important ways. Firstly, the Toronto guidelines highlight the responsibility of clinical teaching staff to serve as appropriate ethical role models for trainees and to provide trainees with an opportunity to discuss an ethical or difficult situation. Secondly, the document outlines how reportage of and response to ethical concerns in clinical education should be managed. The hospital and university should make the trainee and clinical faculty aware of whom to approach with ethical concerns, make provisions for concerned individuals to receive expert counsel from a bioethicist, and ensure that there are no repercussions for a trainee who expresses concerns or invokes reasonable ethical grounds to refuse participation in clinical teaching. The Toronto experience and the resultant guidelines have been cited in subsequent articles and editorials on the ethics of medical education. ${ }^{910}$

\section{Post graduate medical education}

There have been international concerns about the pharmaceutical industry's client building through its relationships with physicians during their specialty training and useful strategies for dealing with it. ${ }^{11-13}$ McCormick et al surveyed specialists in internal medicine who had trained in Toronto and McMaster from 1990 to 1996. ${ }^{14}$ In 1992, McMaster implemented a policy restricting residents' contact with pharmaceutical representatives, while Toronto had yet to promulgate general guidelines about industry interaction. McMaster trained specialists were more sceptical about information from industry and had a slightly lower rate of "contacts" (pharmaceutical company events attended and gifts, honoraria, and consulting fees received). On the other hand, respondents were equally likely to report having met with industry representatives in the preceding year. Greater frequency of contact with pharmaceutical company representatives during training was a predictor of respondents' increased perception that the industry material was beneficial.

Toronto introduced its own measures in 1996 to regulate residents' contact with industry. Trainees are required to disclose the nature of any relationships with industry to patients and to colleagues involved in educational events or research. The guidelines stipulate that trainees cannot receive personal rewards from industry other than educational material of minimal monetary value. More recently, internal medicine residents have received core training in bioethics that includes a forum among residents, at which a pharmaceutical company representative and a bioethicist discuss these matters in depth.

In sum, Toronto's approach is to educate and sensitise trainees rather than to completely restrict access. The goal is to ensure that Toronto trained specialists are equipped to critique industry derived information and to manage conflicts of interest arising from interactions with pharmaceutical representatives.

\section{Graduate education}

During the 1990s, the university issued guidelines for students working in an industrial sponsored environment aimed at ensuring academic progress in a timely fashion with appropriate academic freedom. The medical school amplified and publicised these guidelines. Pursuant to the policy harmonisation process outlined above, the hospitals accepted these and related policies governing University of Toronto graduate students situated on their premises. Moreover, in the last year the medical school has reinforced those guidelines, directing all graduate chairs to ensure that an explicit "contract" is signed between each supervisor and student, with a clause specifying that external support for the students project will not impinge on the student's right to submit a thesis without censorship or delay, or to publish from it in a timely fashion.

\section{Continuing education}

In December 1999, the medical school's continuing education programme promulgated a new and stringent policy for all events involving industry sponsorship. The policy stipulates that the selection of topics, speakers, course materials, and enduring materials is entirely the responsibility of the course organiser. There are constraints on having pharmaceutical representatives as experts or programme planners. Event grants may only be accepted if there are no direct industry payments to organisers or speakers or subsidies for attendees, and if limits can be placed on commercial displays in and around the event. Topics cannot be "product or promotion oriented" and "presentations must give a balanced view of all relevant therapeutic options available". Lastly, any money received from an industry (or any affiliation with an industry) must be declared by the speakers and organisers and disclosed to participants. If there is industry support for an event, this must also be disclosed to participants.

\section{A new dispensation for clinical and organisational affairs}

As already noted, the employment structures for clinical faculty in Toronto and similarly structured health science centres conjoin hospital staff privileges and university appointments. Whereas continuing appointments are the norm for established clinical faculty in the university setting, 
legislation in many jurisdictions requires medical staff to undergo annual hospital renewal. Moreover, in Toronto, the status of academic appointments for clinical faculty is in limbo. A memorandum of agreement between the university and its faculty association stipulates that during the term of the agreement, the university will not change specific policies and practices without mutual consent. For a quarter of a century, however, the extant academic policies have explicitly excluded clinical faculty. Since 1978 they have accessed university dispute resolution mechanisms for faculty/administration disputes, sometimes with the support of the faculty association, but there is no policy framework governing their appointments or the university component of their remuneration. Starting in the 1990s, the medical school introduced a series of divisional practices to fill this vacuum as the frustration of clinical faculty mounted in the face of their ambiguous university status.

In the wake of the deferiprone dispute, Olivieri and two of her colleagues at the Hospital for Sick Children alleged that their annual compensation adjustments through one of that hospital's practice plans were unfairly skewed because of the OAA. Claiming a breach of academic freedom, they launched grievances through the university, seeking external and binding arbitration that would assess and, if needed, redress these claims. The university's arbitration process has no direct jurisdiction over hospitals or practice plans. The grievance document submitted by Olivieri et al in November 2001 sought first to establish such jurisdiction for the university, and then proposed a series of other measures if such jurisdiction could not be readily established. The submission asked that the outcome of the arbitration be the voiding of the affiliation agreement with the Hospital for Sick Children if the hospital and the practice plan did not find a way to accommodate these grievances. The pursuit of these grievances provoked scores of protest letters from clinical faculty to the university president. The Ontario Medical Association and medical staff associations from the other hospitals interceded to warn the university's arbitration panel away from attempted intrusion into practice plans. The grievances were stalled, given the obvious jurisdictional gridlock and mounting political resistance, and have since been withdrawn pursuant to a comprehensive local resolution of the OAA.

Given the adverse reaction from clinical faculty to the grievance by the three colleagues at the Hospital for Sick Children, the continuing policy vacuum, and clear signals that the provincial government wanted to renegotiate the way in which physicians working in academic settings were remunerated, the university established a widely representative task force on clinical faculty in early 2002. The task force rapidly found that clinical faculty overwhelmingly desired their own university policies, independent from those of tenure line faculty, with their own dispute resolution mechanisms and representation.

As the task force noted, the employment circumstances and accountabilities of academic physicians were clearly distinct from tenure line university salaried faculty members. The task force reviewed arrangements in leading US and UK universities, finding limited clarity about the nature of these appointments and jurisdiction on matters such as academic freedom within the clinical setting. Indeed, there was no consensus on the definition of academic freedom, particularly in the clinical sphere.

The task force concluded that academic freedom could not be invoked to trump a clinical faculty member's fiduciary obligation to his or her patients, or to override practice standards or the need for collegial relationships. At the same time, the university had a responsibility to safeguard the academic freedom of all individuals with university appointments engaged full time in academic work regardless of "paymaster". For their part, the hospitals and practice plans were very resistant to granting authority over their operations to a university tribunal, even as they acknowledged the need for an arm's length mechanism to adjudicate academic freedom complaints. The task force accordingly hit on a compromise. A new panel would have the authority to investigate all unresolved grievances involving an allegation of breach of academic freedom in the clinical sphere. It could not, however, enforce remedies. Instead, its judgment on the matter of academic freedom would be binding on all parties, and carried forward, if necessary, to higher levels of dispute resolution in the hospital or practice plan, or to a court of law.

In the last few months, the university, the medical school, hospital CEOs, medical advisory committees, clinical chiefs, practice plan managers, and medical staff associations have all endorsed the task force's recommendations. However, the implementation of these new policies requires the consent of the faculty association, given the "frozen policy" provisions in the memorandum of agreement. The faculty association provided very substantial legal and financial support to Olivieri and supportive colleagues during the OAA, given the principles at stake, but does not wish to be caught in a similar position again. It therefore favours distinct status for clinical faculty but would prefer that the proposed academic freedom tribunal be empowered to award remedies along with its binding judgments. Such remedial powers, however, will never be granted by the hospitals or practice plans. It would be an ironic footnote to the OAA if a hard won policy consensus offering greatly enhanced safeguards for academic freedom in the clinical sphere were to be lost as a result of opposition from the group of colleagues in Toronto who were vocally critical of the university's failure to intercede earlier in the original deferiprone dispute.

\section{Better governance for academic health sciences complexes: some observations}

Good governance from an ethical perspective involves the "translation of collective moral intentions into effective and accountable institutional actions". ${ }^{3}$ Modifying McDonald's concept of "good governance" and institutional ethics for our purposes, ${ }^{3}{ }^{15}$ we see four operational features of good governance: (1) appropriate oversight; (2) sound policies and guidelines; (3) effective implementation of policies and guidelines, and (4) continuous evaluation and feedback.

\section{Appropriate oversight}

Academic health sciences complexes require agreement among the partners to create oversight mechanisms congruent with their unique organisational structures. The form of oversight will depend on where the university/medical school/hospital complex rests on a continuum between operational aggregation and autonomy. The Toronto model reflects a high degree of institutional autonomy, as contrasted with some American centres where the university owns teaching hospitals and hospitals directly manage practice plans. In any system, however, there must be respect for differences in mission and jurisdiction across academic and clinical spheres of activity, and a commitment to clarifying shared values, especially concerning the ethics of research and education and the responsible exercise of academic freedom.

Good governance on ethics issues raises the question of the appropriate role of bioethics centres or programmes. These centres or programmes will clearly need to fulfil not only their traditional roles, but also serve as a resource for the types of activities described above. 
Sound policies and guidelines

Only a few of the policies and guidelines promulgated in recent years in the Toronto academic health system have novel features. Indeed, both the literature and the policies of other institutions have been fruitful sources of information to guide our own policy formulation. What may be more noteworthy is the extent and nature of the engagement with applied ethical issues. As stated in the introduction to this paper, the momentum generated thus far is a direct outgrowth of a proactive ethics approach. That is, without abandoning the principle of individual accountability for decisions and actions, the leadership of the partner institutions should pay less attention to individuals and seek to galvanise systemic reforms. To paraphrase Don Berwick, a leader of the patient safety movement, the remedy is not in individual blame but system redesign. ${ }^{16}$ Bioethics centres can contribute to policy formulation as an expert resource and through their research agendas. In Toronto-for example, the JCB also served as an environment to incubate research on ethical dilemmas that shape medical students' educational experiences, and its members contributed to the development of the guidelines that addressed these dilemmas.

\section{Appropriate implementation}

One lesson of the recent Toronto experience is that the process of formulation bears on the probability of success in implementation. Collaboration and support in Toronto have been attained in many instances by acknowledging challenges in jurisdiction or mission, positioning ethical challenges as integral to the stability of the partnership, and building legitimacy for policies and guidelines through multiinstitutional working groups. This consensus building approach permits decentralisation of implementation, with shared oversight, and avoids the need to create cumbersome and centralised bureaucracies to police ethical behaviour.

The JCB is governed by a council of hospital and university representatives, and has a strong contingent of hospital based clinical bioethicists who are involved in research ethics review and policy making. Thus, the centre's structure reinforces the implementation of ethics oriented governance.

\section{Continuous evaluation and feedback}

New ethical standards and organisational challenges are constantly emerging in academic health sciences centres. By updating policies, auditing compliance, and assessing progress against benchmarks, the partners can continuously enhance and reinvigorate their shared commitment to an ethical environment. It is essential for the evaluation results to be looped back through the institution to aid in the updating of the policies and guidelines. For example, a multisite evaluation as reported by Naylor et al ${ }^{2}$ was used by the TAHSC in updating institutional policies at the academic/ industry interface.

\section{CONCLUSION}

The OAA was a catalyst that accelerated systemic reforms in the Toronto academic health sciences centre. The case exemplified much that can go wrong at the interface of academe and industry. It also underscored the accumulating evidence of a need to rework the social contract among the university, the hospitals, and practice plans. Over the last several years, the Toronto academic health sciences centre has undertaken comprehensive initiatives aimed at strengthening the ethical fabric of the partner institutions in research, education, and clinical affairs. Consistent with the good governance literature, the goal of the participants has been to translate appropriate collective moral intentions into effective and accountable institutional actions that respect and support institutional missions and mandates. While few of the policies are dramatically innovative, what is arguably novel is the elaboration of an overarching governance framework that aims to move ethics to a central focus in the academic health sciences complex. A framework such as this mainstreams an ethics centre and allows it to connect its research on ethical issues to ethics governance.

Our comprehensive initiatives have already created cumulative changes and appear to have a continuing momentum. Time alone will tell how sustainable and effective these changes are.

\section{Authors' affiliations}

L E Ferris, C D Naylor, Faculty of Medicine, University of Toronto, Toronto, Ontario, Canada

P A Singer, Joint Centre for Bioethics, University of Toronto, Toronto, Ontario, Canada

Funding: Dr Singer is supported in part by a Canadian Institutes of Health Research Distinguished Investigator award.

Dr Ferris is Judicial Affairs Advisor in the Faculty of Medicine and Associate Professor in the Department of Health Sciences at the University of Toronto. Professor Singer is Sun Life Financial Chair and Director of the Joint Centre for Bioethics and also Professor of Medicine at the University of Toronto. Dr Naylor is Dean in the Faculty of Medicine and also Vice Provost for Relations with Health Care Institutions, at the University of Toronto.

Declaration of conflict of interest

As Dean/Vice Provost since 1999, CD Naylor was involved with the protracted denovement of the L1-OAA affair.

\section{REFERENCES}

1 Naylor CD. The Deferiprone controversy: time to move on. CMAJ 2002;166:452-3.

2 Naylor CD. Early Toronto experience with new standards for industry sponsored clinical research: a progress report. CMAJ 2002;166:453-6.

3 McDonald M. Canadian governance of human research involving human subjects: is anybody minding the store? Health Law J 2001;9:1-22.

4 Ethics in Action. http://www.library.utoronto.ca/medicine/medUofT/ ethics.html (accessed 17 Oct 2003).

5 Levine JK. Considering alternative organisational structures for academic medical centers. Academic Clinical Practice 2002;14:2-5.

6 Weiner BJ, Culbertson R, Jones RF, et al. Organizational models for medical school-clinical enterprise relationships. Acad Med 2001;76:113-24.

7 Hicks LK, Lin Y, Robertson DW, et al. Understanding the clinical dilemmas that shape medical students' ethical development: questionnaire survey and focus group study. BMJ 2001;322:709-10.

8 Doyal L. Closing the gap between professional teaching and practice. BMJ 2001;322:685-6.

9 Coldicott $Y$, Pope $C$, Roberts $C$. The ethics of intimate examinations-teaching tomorrow's doctors. BMJ 2003;326:97-101.

10 Singer PA. Intimate examinations and other ethical challenges in medical education. BMJ 2003:326:62-3.

11 Razack S, Arbour L, Hutcheon R. Proposed model for interaction between residents and residency training programs, and pharmaceutical industry. Ann R Coll Physicians Surg Can 1999;32:93-6.

12 Education Council, Residency Training Programme in Internal Medicine, Department of Medicine, McMaster University, Hamilton, Ont. Development of residency program guidelines for interaction with the pharmaceutical industry. CMAJ 1993;149:405-8.

13 Forrest DM, Ruedy J. Proposed guidelines for house staff interaction with pharmaceutical companies. Ann R Coll Physicians Surg Can 1994;26:291-3.

14 McCormick BB, Tomlinson G, Brill-Edwards P, et al. Effect of restricting contact between pharmaceutical company representatives and internal medicine residents on post-training attitudes and behavior. JAMA 2001;286:1994-9.

15 McDonald $M$. The governance of human research involving human subjects. Ottawa: Law Commission of Canada, 2000.

16 Berwick DM. Not again! Preventing errors lies in redesign not exhortation. BMJ $2001 ; 322: 247-8$. 